\title{
Together But Alone: Atomization and Peer Support among Gig Workers
}

\author{
ZHENG YAO, Carnegie Mellon University, USA \\ SILAS WEDEN, Smith College, USA \\ LEA EMERLYN, Carnegie Mellon University, USA \\ HAIYI ZHU, Carnegie Mellon University, USA \\ ROBERT E. KRAUT, Carnegie Mellon University, USA
}

The individualistic nature of gig work allows workers to have high levels of flexibility, but it also leads to atomization, leaving them isolated from peer workers. In this paper, we employed a qualitative approach to understand how online social media groups provide informational and emotional support to physical gig workers during the COVID-19 pandemic. We found that social media groups alleviate the atomization effect, as workers use these groups to obtain experiential knowledge from their peers, build connections, and organize collective action. However, we noted a reluctance among workers to share strategic information where there was a perceived risk of being competitively disadvantaged. In addition, we found that the diversity among gig workers has also led to limited empathy for one another, which further impedes the provision of emotional support. While social media groups could potentially become places where workers organize collective efforts, several factors, including the uncertainty of other workers' activities and the understanding of the independent contractor status, have diminished the effectiveness of efforts at collective action.

\section{CCS Concepts: • Human-centered computing $\rightarrow$ Empirical studies in HCI.}

Additional Key Words and Phrases: social support; peer support; online community; gig work; gig economy

\section{ACM Reference Format:}

Zheng Yao, Silas Weden, Lea Emerlyn, Haiyi Zhu, and Robert E. Kraut. 2021. Together But Alone: Atomization and Peer Support among Gig Workers. Proc. ACM Hum.-Comput. Interact. 5, CSCW2, Article 391 (October 2021), 29 pages. https://doi.org/10.1145/3479535

\section{INTRODUCTION}

"Drive when you want. Earn what you need."

Uber displays this slogan on its website, encouraging drivers to sign up and offering them a sense of personal autonomy. Indeed, a variety of online platforms now function as intermediaries between labor supply and demand, in which mobile applications provide small tasks or 'gigs' such as driving, delivery, and handyman work to individuals [79]. With the app-mediated model, individual contractors gain flexibility in terms of work schedule, deciding when and how much they want to work, as illustrated by Uber's slogan [36, 60, 81]. However, the independent contractors' status also results in an atomized labor force. Workers are rarely in the same physical space, and

\footnotetext{
${ }^{1}$ https://www.uber.com/a/us/

Authors' addresses: Zheng Yao, zyao2@cs.cmu.edu, Carnegie Mellon University, USA; Silas Weden, sweden@smith.edu, Smith College, USA; Lea Emerlyn, Carnegie Mellon University, USA, leas@andrew.cmu.edu; Haiyi Zhu, Carnegie Mellon University, USA, haiyiz@cmu.edu; Robert E. Kraut, Carnegie Mellon University, USA, robert.kraut@cmu.edu.
}

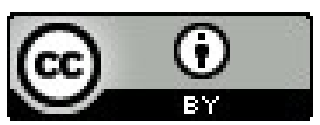

This work is licensed under a Creative Commons Attribution International 4.0 License.

(c) 2021 Copyright held by the owner/author(s).

2573-0142/2021/10-ART391. https://doi.org/10.1145/3479535

Proc. ACM Hum.-Comput. Interact., Vol. 5, No. CSCW2, Article 391. Publication date: October 2021. 
companies and workers principally interact via digital interfaces, which typically do not support worker-to-worker communication [88]. The role of a human supervisor is replaced with digital systems, and workers interact almost exclusively with the app, which allocates the work, and not with a human supervisor or with co-workers [44]. Additionally, because most tasks are small and straightforward, workers typically complete their tasks independently and rarely collaborate with one another.

This atomization aggravates informational asymmetry, which, as a result, leads to severe power asymmetry and emotional challenges for gig workers. Gig workers experience informational and power asymmetries with respect to work platforms, as companies usually are secretive about how the algorithms allocate jobs and also do not encourage in-app communication among workers $[45,46]$. As a result, gig workers are largely on their own in navigating their work and relationships with their employers. Workers find it difficult to understand how their individual activities fit within a broader picture and how they relate to other workers [88]. The lack of meaningful social and collegial relationships in the workplace could also prevent workers from providing the necessary emotional support to one another[47]. This isolation, coupled with gig workers' employment status as independent contractors without collective bargaining rights nor union representation rather than employees [24, 81], presents significant obstacles to workers' collective organizing [20, 88] Given that digital platforms control the allocation of jobs, workers might be less inclined to take cohesive collective action against management for fear of retribution [81].

Recent evidence from a study of gig workers suggested that social media groups have the potential to facilitate information exchange, emotional support, coordination, and collective action among gig workers, and can help them form new kinds of group social identities [44, 56]. However, little is known about the extent to which social media groups help gig workers cope with their challenges and whether gig workers actually perceive such peer support as useful. It is also unclear whether and how physical gig workers (e.g., Uber/Lyft drivers and Instacart workers) would use social media groups to organize collective labor actions such as offline strikes.

This paper is a qualitative study to understand how online social media groups provide informational and emotional support to physical gig workers and evaluate whether social media groups could help workers with collective actions. Results show that social media groups can serve as platforms where gig workers exchange information, build connections, and organize collective action. While workers frequently exchange concrete experiential knowledge with peers, they are less likely to share difficult to obtain information or to share with people who might compete with them. In addition, because of the competitive nature of gig work, the diversity among workers, and their portrayal as independent contractors, the workers seem to have limited empathy with each other, which impedes the exchange of emotional support. While social media groups could potentially serve as platforms where workers organize collective efforts, several factors, including difficulties assessing other workers' sentiments and activities, prevent that from happening. Our work makes the following contributions to the CSCW literature:

- First, a combination of interviews and content analysis of public posts presents a holistic picture of the informational and emotional support exchanged in the social media groups and how gig workers perceive this support.

- Second, in addition to recognizing the benefits provided by social media groups, this research examines the limitations of these groups and discusses the implications.

- Lastly, the findings contribute observations of how gig workers use social media groups for labor strikes. 


\section{RELATED WORK}

This section defines physical gig work and explains why it is important to focus on this segment of gig workers. It then examines challenges, including economic uncertainties (i.e., precarity) and uncompensated emotional labor, that physical gig workers face. It also discusses how collective action could be a solution to improve workers' working conditions, and how atomization can inhibit collective action and exacerbate other problems. Lastly, it analyzes the affordances of social media and draws on the prior success of social media groups in other contexts to discuss the ways in which these groups can potentially help resolve some of gig workers' challenges.

The gig economy refers to the collection of markets that match service providers with consumers needing discrete tasks to be accomplished through on-demand platforms [19]. Depending on how the gig service is fulfilled, gig workers can be roughly divided into two categories: physical gig workers (whose work is conducted offline and locally) and virtual workers (whose work is performed online) [17, 82]. Physical gig work consists of transportation services (e.g., Uber and Lyft), delivery services (e.g., Instacart, Doordash, Grubhub), as well as household and personal services (e.g., Taskrabbit, care.com)[48]. Because the COVID-19 pandemic presented unique challenges to physical gig workers, who often risk exposure to the virus in the course of their work, this paper tries to understand how gig workers dealt with these new challenges and the resources they leveraged for success. It also explores how CSCW systems could help.

\subsection{Challenges faced by gig workers}

Prior research has found that being a physical gig worker can often lead to challenging and frustrating experiences. First and foremost, physical gig work is known for its precarity [20, 36, 80, 88]. According to Vosko [86], a job is considered precarious if it shows at least two out of the following four dimensions: low wages; high employment insecurity; low levels of employee control over wages, hours, and working conditions; and a lack of regulatory protection. Studies have shown that physical gig workers face low wages [8]. ${ }^{2}$. As independent contractors, in most of the United States, gig workers are not protected by minimum wage standards and thus face income uncertainty based on the whim of the market [48]. For example, if there is no market demand, drivers may end up waiting in lines, wasting time and gas, and driving an empty car for some unpredictable time period of the day [3]. Moreover, gig workers typically do not receive employee benefits, such as health insurance, and are expected to cover their own expenses, such as gas expenses and vehicle depreciation as well [50]. Such precarity is even more harmful during a major public health crisis, like COVID-19. A San Francisco-based survey demonstrated that ride-hail drivers' earnings plummeted amid virus-related social distancing measures and lockdowns even as they were exposing themselves to increased health risks [7]. A number of reports also emerged in the earliest stages of the pandemic, showing that physical gig workers were short of personal protective equipment and did not have coverage for paid sick leave and health insurance $[15,18]$.

Besides precarity, the working conditions of physical gig workers are also far from ideal. For example, because rideshare drivers' work often involves dealing with the public in isolation, they risk abuse at different levels of severity, ranging from verbal abuse to physical assaults [5] and sexual harassment [39]. Moreover, physical gig workers are often the victims of racial discrimination, as reflected in limited working opportunities, lower rating [32], and lower market prices for underrepresented populations [21].

Physical gig workers must also perform emotional labor (i.e., the process of managing one's feelings as part of one's professional role) [33]. Although other workers, like flight attendants,

\footnotetext{
${ }^{2}$ A 2019 study shows that delivery gig workers in the U.S. earn an average hourly wage of $\$ 17.10$, handyman gig workers $\$ 16.71$, and driver gig workers $\$ 14.31$, less than two-thirds of the average hourly wage of $\$ 25.33$ for online freelancers' [23]
} 
receptionists, and taxi drivers, must perform emotional labor, it affects the physical gig workers far more severely because customer ratings of them impact all aspects of their jobs [26, 61, 72]. For example, ratings below a certain cut-off can result in severe consequences for drivers, including low priority order assignment and even deactivation. Because these customer ratings are a form of performance surveillance, physical gig workers must carefully attend to the social and emotional needs of their consumers [11]. Consumers, on the other hand, are rarely informed about the importance of their ratings, despite the power they have to impact workers' jobs [72]. Additionally, unlike, say, taxi drivers who need to take a city-required training course (with topics related to emotion management included), physical gig workers, who are untrained in this area, are nonetheless expected to exert such emotional labor in appeasing the needs of their customers [66]. Such poor working conditions, along with the emotional labor workers must perform, are associated with negative psychological outcomes such as anxiety and decreased psychological resilience $[6,50,60,78]$.

Information asymmetry is another core challenge faced by gig workers [52, 59]. Algorithmic management allows gig platforms to automatically organize and coordinate large numbers of workers in a highly effective manner, but the platforms are usually secretive about the algorithms that determine how jobs are allocated [45]. Because of the lack of transparency, workers find it difficult to interpret the decisions made by the algorithms. Such information asymmetry clearly favors the gig platforms' interests because it undermines workers' ability to make rational decisions and develop corresponding strategies [55]. Because if rideshare drivers have little insight into how passengers are assigned, they cannot consciously strategize about which trips are more profitable to take and which should be avoided [73]. A strike in May of 2019 organized by rideshare drivers explicitly targeted information asymmetry and demanded data transparency.

\subsection{Collective action and atomization in the gig economy}

Collective labor activities, such as negotiations, work actions, strikes, and unionization campaigns, are ways for workers to advocate for better working conditions [27, 51]. In the last several years, gig workers have initiated collective action, aiming for pay raises, insurance and health benefits, and to legitimize their status as employees. Collective action has led to mixed outcomes. For example, while U.K.'s Supreme Court reaffirmed earlier rulings that rideshare drivers are employees instead of independent contractors[70], the 'Proposition 22' voter referendum in California, which was heavily supported by Uber, Lyft and other gig platform companies and opposed by labor groups like Gig Workers Rising, overturned a state law classifying gig workers as employees [1, 69]. The gig platforms have been actively hostile to worker organizing, by confronting worker organizing efforts [2] and by lobbying to push back legislation that was resulted from that worker organization. In addition to the obstacles posed by the platforms, the geographical dispersal of gig workers (i.e., atomization) also obstructs collective action because geography limits the communication among workers $[14,20,84,88]$. Indeed, most gig platforms do not facilitate in-app communication among workers. This separation is further exacerbated by the typically simple, individualistic nature of physical gig tasks, which reduces collaboration and interaction among workers and thus opportunities for collective action. Although prior literature noted that 'spatial proximity and temporal synchronicity' could alleviate the atomization effect for physical gig workers [92], COVID-19 has further isolated gig workers from one another.

Atomization (i.e., the isolated and individualized nature of gig work) seems to exacerbate a number of problems faced by gig workers [4]. First, atomization limits workers' opportunities to obtain task-related information from their peers, making it more difficult for them to understand how their individual activities fit within a broader picture, ultimately worsening the information asymmetry and power imbalance between workers and platforms [44, 88]. Second, prior literature

Proc. ACM Hum.-Comput. Interact., Vol. 5, No. CSCW2, Article 391. Publication date: October 2021. 
suggests that meaningful social and collegial relationships in the workplace can buffer the effects of work-related stress [47]. The lack of meaningful social interaction with supervisors and colleagues might lead gig workers to experience feelings of loneliness and might cut off the potential avenues through which workers could provide support for one another [90]. Third, as discussed above, though the diversity of worker backgrounds and motivations have already made it difficult for workers to identify targets for collective action, atomization only makes this issue more difficult, as it, again, hinders communication among peer workers [64]. In summary, atomization is not simply a lack of fixed physical workplaces, but also the absence of viable worker networks [83]. Without an effective social network, gig workers have difficulty accessing resources (e.g., useful information or emotional support) available from their social ties, such as supervisors and coworkers [37].

\subsection{Social media groups as a supporting infrastructure for gig workers}

As independent contractors, physical gig workers only obtain limited support and resources from their gig platforms. Structurally, gig platforms are typical examples of risk transference [60], where they displace the risk and responsibility from the company to the independent contractors. Thus, gig workers are unlikely to receive benefits like health insurance and paid sick leave like their counterparts in traditional companies, though a number of platforms (including Uber, Lyft, Instacart, and Doordash) have issued policies that offer some of these benefits in limited circumstances in response to COVID-19 (see [40, 42, 43]). Moreover, informational support is provided to workers typically in the forms of textual frequently asked questions (FAQ) lists (available in the help menu of the applications), telephone hotlines, and local service hubs [59]. However, most of these local offices, such as Uber's Green Hubs, were temporarily closed during the COVID-19 pandemic [41].

The Internet has the potential to help gig workers overcome some of the problems of atomization. Given the limited external support available, we expect that online social support, especially peer support, would be particularly important for physical gig workers. Social media groups hosted by Facebook and Reddit are known to facilitate access to social support and to broaden the resources that the members have access to $[16,85]$. The affordances of social media groups, such as high visibility and long persistence [9], are particularly well suited for maintaining a loosely tied community [25], and thus seem promising in alleviating gig workers' atomization.

Indeed, some prior studies have identified social media groups as useful platforms for providing social support to independent workers, including Amazon Mechanical Turk(mTurk) workers [74], Airbnb hosts [34], rideshare drivers [5, 49, 53, 72], and online freelancers [91]. First, gig workers can leverage these groups for their informational needs. For instance, rideshare drivers are known to communicate via these groups to share experiences, gain insights, and discuss their workarounds for common challenges they face. Important topics such as the surging price mechanism, safety measures, and Uber rules and regulations are also covered [5, 49]. Social media groups also provide emotional support to gig workers [5,34,53]. As gig work is often regarded as low-status, social media offers workers a safety net where they are less likely to be judged as some might fear stigmatization by their strong tie networks such as family and friends [56]. By listening to one another's experiences, members in social media groups can provide emotional support to one another by allowing their peers to vent their frustrations and potentially devise workarounds $[5,34,53]$. Limiting platform access to individuals who share similar experiences also brings in a sense of community and social inclusion, which might help workers cope with the social isolation they face [76].

However, we also identified gaps in the prior research. First, existing research has focused mainly on the potential benefits of social media groups in facilitating peer support. Little is known about how gig workers actually perceive peer support and the limitations of social media groups in helping gig workers cope with their challenges. Second, it is generally acknowledged that the 
atomization of gig workers makes it difficult to coordinate collective activity across dispersed, individual workers, but it is not clear if social media groups are a solution [84, 89]. Lastly, while social media groups have been recognized as playing a central role in structuring and organizing labor activities among virtual gig workers (e.g., mTurk workers [74], and online freelancers [91]), it is unclear whether and how the physical gig workers (e.g., Uber/Lyft drivers and Instacart workers) would use social media groups to organize offline strikes. In this paper, we study how isolated gig workers use social media groups on Facebook and Reddit to mitigate the challenges they are facing. We want to answer the following research questions:

(1) How is peer support exchanged among gig workers in social media groups?

(2) Do gig workers perceive such peer support as helpful? What are the limitations of these groups?

(3) How do gig workers use social media groups to organize collective actions (e.g., offline strikes in particular)?

\section{METHOD}

In this study, we conducted semi-structured interviews with 20 physical gig workers from the United States. We also performed a content analysis on posts from social media groups. We first analyzed 173 posts extracted from a semi-public Facebook group for rideshare drivers in New York City to develop a codebook. We then applied the codebook to 162 posts on the subreddit r/Uberdrivers, and 1,321 posts from 8 diverse Facebook groups before and during the pandemic. Additionally, we examined two strike incidents initiated by physical gig workers. The first strike took place in May 2019, right ahead of Uber's IPO[68]. The second strike occurred in March 2020, when Instacart shoppers chose to strike due to the company's failure to provide them with hazard pay and personal protection equipment [75]. For each strike, we extracted relevant posts from their corresponding subreddit (i.e., r/uberdrivers and r/InstacartShoppers) and analyzed their replies to examine how online group members reacted to the strike.

\subsection{Interview}

We conducted an interview study to understand how physical gig workers obtain social support, and in particular, how social media groups provide informational and emotional support to them. We also asked questions related to collective action and strikes. The first author joined multiple local and nationwide Facebook groups for rideshare drivers to observe the interactions within these groups. Four in-person formative interviews were carried out in February 2020 with drivers from the authors' local regions. With the unexpected COVID-19 crisis, we restructured and expanded the scope of our study to include other physical gig workers (i.e., delivery people and handymen) in addition to rideshare drivers. In order to understand how COVID-19 has affected their work and lives, another three formative interviews were conducted in April 2020 with local rideshare drivers. Our near-year-long observation of gig worker communities, along with seven formative interviews, have greatly informed our interview protocols. We used COVID-19 as a basis for examining the process by which workers obtain informational and emotional support to cope with new challenges. The interview protocol included questions about how interviewees typically acquired general support acquisition (e.g., "if you need to obtain information about your work, where do you go?"), as well as how social media groups play a role in supporting their work (e.g., "Can you describe to me how you would typically participate in these groups? Can you describe to me one post that you found the most helpful in these groups?"). All interviews reported in this work were conducted via Zoom audio call in July 2020, just as the U.S. reached a monthly record of 1.9 million new COVID-19 cases [12]. 
We aim to cover three types of physical gig workers in this study: rideshare drivers, food delivery workers, and handymen. We recruited participants using both online and offline methods. For online recruitment, we posted open recruitment messages in relevant Facebook groups. Groups on Reddit tended to be more restrictive about recruitment of this type, so we took a different approach with Reddit recruitment by sending direct messages to members of relevant gig work subreddits (e.g., $\mathrm{r} /$ uberdrivers and $\mathrm{r}$ /instacartshoppers). For offline recruitment, we employed snowball sampling (similar to [53]). Thus, these participants did not necessarily belong to the same online groups as the interviewees who referred them. We recruited other offline participants, in particular, Taskrabbit workers, by reaching out to the participants directly using the application. This approach was especially useful because the social media groups for the handyman workers were not as active as the other two (e.g., rideshare drivers and food delivery workers). As of Oct 15, 2020, r/Taskrabbit has about 1800 members while r/InstacartShoppers has 36.8k). In addition to these two primary methods of recruitment, one participant was recruited directly as a friend of a member of one of the members in our research group. Although the goal of the study is to evaluate how online social media groups provide support to gig workers, we found it important to talk to those workers who did not participate in online groups as well, to ask questions about why these groups are not particularly helpful to them. Sixteen of the interviewees were members of one or more social media groups, and four reported having not participated in any before. The combination of online and offline recruitment thus yields a more diverse participant pool with differing amounts of experience in using work-related online groups.

We present the demographic information of our interviewees in Table 1. The participant pool consisted of 20 gig workers from across the United States, with five working for at least one rideshare company, and six working for a gig platform like Taskrabbit that favors handyman-type work. Of the 14 participants that worked in food delivery, five worked for Doordash, four worked for Instacart, and four worked for both, making them the two most popular gig platforms among our pool. Most were currently working for at least one gig platform at the time of the interviews in July 2020. Thirteen participants did gig work part-time alongside another, typically more traditional job, while only five considered their gig work to be full-time jobs. Two participants described themselves as "mixed," meaning they did gig work part-time during the school year and full-time over school breaks. Thirteen participants engaged in gig work before the COVID-19 pandemic hit the country, while seven began doing gig work after the pandemic took hold. We defined "before" COVID-19 as before March 1, 2020. Any participant who did not start gig work until after that date was designated as starting "after" COVID-19.

Before launching the data analysis, the research team held brief discussion sessions following every interview. More exhaustive weekly meetings were organized starting the first week of data collection. During the meetings, the research team gathered virtually to discuss emerging codes and themes from the interview. All interviews were audio-recorded and transcribed after the data collection was wrapped up. Guided by grounded theory [13], the three independent, trained coders started the inductive, open-ended qualitative coding by tagging topics in the transcripts. In this study, our goal is to examine how peer social support is exchanged and how collective action is organized in social media groups among physical gig workers. Thus, in our analysis, we naturally followed the classic categorization of social support [77] and paid attention to two types of social support that were most commonly studied in online spaces-informational and emotional support -in addition to collective action. With these three initial categories, we then developed a codebook iteratively, starting with topics of interest based on prior discussions and existing literature. Those topics include the affordances of social media and the relationship between peer support and other sources of support. After multiple iterations of analysis, we grouped a total of 29 subthemes underneath the three categories and extracted key quotes to illustrate our findings. 


\begin{tabular}{|c|c|c|c|c|c|c|c|}
\hline ID & Companies & Company Type & $\begin{array}{l}\text { Full / Part } \\
\text { Time }\end{array}$ & B/A Mar 20' & State & Recruitment & $\begin{array}{l}\text { SNS Group } \\
\text { Member }\end{array}$ \\
\hline $\mathrm{P} 1$ & $\begin{array}{l}\text { Uber, } \\
\text { UberEats }\end{array}$ & $\begin{array}{l}\text { rideshare, } \\
\text { Food Delivery }\end{array}$ & $\mathrm{P}$ & Before & ME & Offline & $\mathrm{N}$ \\
\hline $\mathrm{P} 2$ & Lyft, VIA & rideshare & $\mathrm{F}$ & Before & $\mathrm{NY}$ & Online & $\mathrm{Y}$ \\
\hline P3 & Uber, Lyft & rideshare & $\mathrm{F}$ & Before & $\mathrm{CA}$ & Online & $\mathrm{Y}$ \\
\hline $\mathrm{P} 4$ & $\begin{array}{l}\text { Taskrabbit, } \\
\text { Rover }\end{array}$ & Handyman & $\mathrm{P}$ & After & PA & Offline & $\mathrm{N}$ \\
\hline P5 & Taskrabbit & Handyman & $\mathrm{P}$ & After & $\mathrm{PA}$ & Offline & $\mathrm{Y}$ \\
\hline P6 & Taskrabbit & Handyman & $\mathrm{P}$ & After & PA & Offline & $\mathrm{N}$ \\
\hline P7 & $\begin{array}{l}\text { Taskrabbit, } \\
\text { Rover }\end{array}$ & Handyman & $\mathrm{P}$ & Before & PA & Offline & $\mathrm{Y}$ \\
\hline P8 & $\begin{array}{l}\text { Taskrabbit, } \\
\text { Postmates, } \\
\text { Airbnb }\end{array}$ & $\begin{array}{l}\text { Handyman, } \\
\text { Food Delivery }\end{array}$ & $\mathrm{P}$ & After & PA & Offline & $\mathrm{Y}$ \\
\hline P9 & $\begin{array}{l}\text { Uber, } \\
\text { Doordash, } \\
\text { Postmates, } \\
\text { Taskrabbit }\end{array}$ & $\begin{array}{l}\text { rideshare, } \\
\text { Food Delivery, } \\
\text { Handyman }\end{array}$ & $\mathrm{P}$ & Before & PA & Offline & $\mathrm{Y}$ \\
\hline P10 & $\begin{array}{l}\text { Instacart, } \\
\text { UberEats, } \\
\text { Doordash, } \\
\text { Postmates }\end{array}$ & Food Delivery & $\mathrm{P}$ & After & NY & Online & $\mathrm{Y}$ \\
\hline P11 & Instacart & Food Delivery & $\mathrm{F}$ & Before & $\mathrm{NY}$ & Online & $\mathrm{Y}$ \\
\hline $\mathrm{P} 12$ & $\begin{array}{l}\text { Instacart, } \\
\text { Doordash, } \\
\text { Postmates, } \\
\text { Shipt }\end{array}$ & Food Delivery & $\mathrm{P}$ & Before & NY & Online & $\mathrm{Y}$ \\
\hline P13 & Instacart & Food Delivery & $\mathrm{P}$ & After & $\mathrm{NY}$ & Online & $\mathrm{Y}$ \\
\hline P14 & $\begin{array}{l}\text { Instacart, } \\
\text { Doordash, } \\
\text { Grubhub }\end{array}$ & Food Delivery & $\mathrm{P}$ & Before & MI & Online & $\mathrm{Y}$ \\
\hline P15 & $\begin{array}{l}\text { Instacart, } \\
\text { Grubhub, } \\
\text { Doordash, } \\
\text { UberEats }\end{array}$ & Food Delivery & Mixed & Before & GA & Online & $\mathrm{Y}$ \\
\hline P16 & $\begin{array}{l}\text { Ubereats, } \\
\text { Doordash }\end{array}$ & Food Delivery & Mixed & Before & SC & Online & $\mathrm{Y}$ \\
\hline P17 & Doordash & Food Delivery & $\mathrm{P}$ & Before & IN & Offline & $\mathrm{Y}$ \\
\hline P18 & Doordash & Food Delivery & $\mathrm{P}$ & After & MI & Offline & $\mathrm{N}$ \\
\hline P19 & $\begin{array}{l}\text { Instacart, } \\
\text { Postmates, } \\
\text { UberEats, } \\
\text { Doordash }\end{array}$ & Food Delivery & $\mathrm{F}$ & Before & $\mathrm{AZ}$ & Online & $\mathrm{Y}$ \\
\hline P20 & $\begin{array}{l}\text { Uber, } \\
\text { Instacart, } \\
\text { Grubhub }\end{array}$ & $\begin{array}{l}\text { rideshare, } \\
\text { Food Delivery }\end{array}$ & $\mathrm{F}$ & Before & $\mathrm{CA}$ & Online & $\mathrm{Y}$ \\
\hline
\end{tabular}

Table 1. Recruitment demographic for Interviewees 


\begin{tabular}{|l|l|l|}
\hline Group Name & \# of members & Group Type \\
\hline Uber/Lyft Drivers Facebook Group & 16,000 & Nationwide group \\
\hline UBER DRIVERS & 28,000 & Nationwide group \\
\hline Uber \& Lyft Drivers Los Angeles & 12,000 & Metropolis local group \\
\hline $\begin{array}{l}\text { UBER,VIA,LYFT, DRIVERS } \\
\text { IN NEW YORK CITY }\end{array}$ & 11,000 & Metropolis local group \\
\hline Florida - Uber Lyft Drivers & 6,300 & State-wide local group \\
\hline Arizona Lyft-Uber Drivers & 2,500 & State-wide local group \\
\hline Pittsburgh Uber & 1,200 & City local group \\
\hline Uber \& Lyft Drivers Seattle/WA & 3,900 & City local group \\
\hline
\end{tabular}

Table 2. We collected a total of 1,321 more posts from 8 Facebook groups in December 2019 and December 2020. This table contains the details of these Facebook groups.

\subsection{Content Analysis}

In addition to the interview study, we also collected posts from both relevant Facebook groups and subreddits to examine workers' interactions and behavior in social media groups. Facebook and Reddit are both grassroots-based, meaning they are not associated with any of the gig work platforms.

Data collection was conducted in two rounds. In the first round, we collected a total of 173 posts between April 20, 2020, and May 15, 2020, in the Facebook group organized by drivers near the New York City area ${ }^{3}$. The qualitative analysis was conducted using a combination of provisional coding and open-coding [49]. Similar to the analysis of our interview data, we followed the definition and categorization of social support and thus focus on the informational and emotional aspects of peer support. Two independent coders started to develop codebooks with the first 85 posts in the Uber NYC group. Afterward, the coders discussed the codes, resolved the conflicts, collectively developed a new codebook with consolidated codes, definitions, and examples, and applied the new codebook to the remaining 88 Facebook posts. The group performed another check-up after finishing coding the entire Uber NYC group dataset to resolve conflicts and refine the codebook.

After developing the codebook, we used a deductive coding approach, applying it to two more datasets. The first includes 162 posts collected from r/uberdrivers ${ }^{4}$ in March 2020. The second contained 1,321 posts from 8 more Facebook groups to account for the diverse types of gig driver groups that co-exist on Facebook. Specifically, we selected Facebook groups at four geographic levels-nationwide, metropolis level local, state-wide local, and city local-and local group in different regions of the United States. Table 2 summarizes the ten Facebook groups from which we collected additional data. In addition, we also took into account that workers' experiences might be very different because of COVID-19. Hence, we sampled data both before (December 2019) and after (December $2020^{5}$ ). Since we did not find a significant difference in the pattern of support exchange between Facebook groups and Reddit, or among the Facebook groups, all three data sets were merged when reporting the final analysis.

Table 3 presents an overview and counts of our codes. We grouped the posts into actions based on the type of social support they provided, namely informational support, emotional support, and tangible support. Note that the total of the percentages might exceed $100 \%$, because some posts

\footnotetext{
${ }^{3}$ UBER,VIA,LYFT, DRIVERS IN NEW YORK CITY, referred to as the Uber NYC group in the rest of the paper

${ }^{4} \mathrm{r}$ /uberdrivers is the largest and most active community among all social media groups dedicated to rideshare drivers, as it has about 165,0000 subscribers and averages around 40 posts per day

${ }^{5}$ when the number of COVID-19 cases reached all-time high in the U.S.
} 


\begin{tabular}{|c|c|c|c|c|c|}
\hline Type & \multicolumn{5}{|c|}{ Informational support } \\
\hline Code & \multicolumn{2}{|c|}{ Seek experience } & Seek solution & Share external info & Share experience \\
\hline Count (\%) & \multicolumn{2}{|c|}{$349(21.1 \%)$} & $433(26.1 \%)$ & $197(11.9 \%)$ & $346(20.9 \%)$ \\
\hline Type & \multicolumn{3}{|c|}{ Emotional Support } & \multicolumn{2}{|c|}{ Tangible support and commercial } \\
\hline Code & Humor & & Compassion \& Prayer & Offer tangible support & Commercial \\
\hline Count (\%) & $142(8.6 \%)$ & 329 & $61(3.7 \%)$ & $7(0.4 \%)$ & $54(3.3 \%)$ \\
\hline
\end{tabular}

Table 3. Content Analysis Codes for 1,321 social media groups posts collected from Facebook and Reddit

and comments belonged to more than one category. We will explain and delve deeper into these codes in the results section.

To understand the impact of social media on collective labor rights activities, we collected posts related to two strikes initiated by physical gig workers. The first happened in May 2019, which was right before Uber's IPO; rideshare drivers intended to 'send a message' to the tech giant, expressing their demands of livable incomes, job security, among other things [68] ${ }^{6}$ The second took place in late March 2020, when Instacart workers led a strike to demand expanded sick pay, more companyprovided personal protective equipment, and an increase in the default tip percentage on orders $[75]^{7}$.

We identified 7 and 10 relevant posts on the subreddit $r /$ uberdrivers and $r$ /nstacartShoppers, respectively, by searching for the keyword "strike" in posts and selecting those that were posted around the strike time and with over 30 comments. For each of these posts, we picked the 10 most up-voted comments for further analysis. For the strike-relevant posts, two independent coders followed an open coding procedure to identify themes focusing on members' attitudes towards the strike with the 100 comments relevant to the Instacart strike. A third coder applied the codebook to the posts collected from the Uber IPO strike and refined its details. In addition, for each reply, we coded each message to determine whether the commenter participated in the strike and whether they held a positive opinion toward it.

\section{RESULTS}

In general, the results show that social media groups on Reddit and Facebook help connect workers to other workers in order to expand their professional social networks. Given the solitary nature of gig work, gig workers typically work in isolation. The interviewees reported that they have small social networks of other gig workers, usually consisting of acquaintances whom they knew personally. For interviewees who did know other gig workers personally, the majority (12 out of 15) mentioned that they did not meet their "gig friends" through their gig jobs, but simply happened to have pre-existing friends or family members who did gig work. P1, an experienced, part-time rideshare driver stated in 2016, said: "I have a pretty significant network of friends that do similar work. And we're not friends necessarily because we do the same work. We just happen to know each other."

Although social media groups connect gig workers with one another and potentially facilitate the exchange of support among peer workers, only a small portion of gig workers participate in these groups. For example, although Uber is said to have had 750,000 drivers total in the U.S. in 2017 [67], the subreddit r/uberdrivers has approximately 68,000 users, and UBER DRIVERS, one of the major nationwide U.S. Facebook groups for rideshare drivers, has approximately 28,000 members. Among the 16 interviewees who were members of social media groups, ten stated that

\footnotetext{
${ }^{6}$ refereed as the Uber IPO strike below

${ }^{7}$ refereed as the Instacart strike below
} 
they discovered these social media groups accidentally, either while searching for information via search engines or upon being referred by a gig friend. Other interviewees relied on their prior experience with social media to locate useful resources. For example, P15 said: "So I was like, I'm sure there's going to be channels in here for these gig jobs. I use Twitter and Reddit the most from a social media standpoint. I assumed that I would be able to find a channel on Reddit for it." In contrast, the gig platforms typically do not provide direct links to grassroots support groups, and none of our participants stated that they located these groups through the platforms' official channels.

In the following sections, we draw results from the interview and the content analysis and examine the effectiveness and constraints of social media groups as platforms for physical gig workers to exchange informational and emotional support as well as to organize collective action.

\subsection{Informational Support}

4.1.1 The concrete and experiential knowledge that peer workers gather from one another supplements the information that they receive through the official channels of the platform. Interviewees reported that they used multiple channels where they were able to obtain task-related information, including personal observation and reflection, authoritative government information, gig platforms' official Q\&A sites and support hotlines, and social media groups. While most of them (12 interviewees) believed the platform-based channels were sufficient for both beginning the job (i.e., on-boarding) and routine operation, these channels were not adequate when gig workers encountered unusual problems. Interviewees complained that the platform-provided information mostly consisted of formally-written instructions and other resources that were difficult to comprehend, and 'only [seemed to be] there for PR [public relation] purpose' (P14). They also noted that platforms took too long to reply to specific, often in-situ questions. Any help that they did receive was often not satisfactory as the platform support hotline operators took too long to resolve their issues. For example, P13 described how Instacart's official support failed to assist her when she was unable to deliver an order to a client: "And [Instacart's support] is outsourced somewhere in the world and 99\% of the time, they are no help. Or if they are [able] to help, they take a long time to help. So, that's time you're wasting when you could be doing another order."

These evaluations of the official support help set the stage and provide a rationale for how social media groups supplement other information already available to workers. Our findings show that peer workers were able to provide concrete, personalized, and experiential information, which complemented the limited information contained in more official sources. Below, we show four major types of posts that lead to gig workers' information-sharing in social media groups, as shown in Table 4. Among them, posts in which users are seeking solutions, seeking experiences, and sharing experiences all reflect instances in which users require personalized, specific information to address issues with the platform. Only the posts in which users are sharing external resources can result in generic information.

- Seeking solutions. Workers often directly ask questions in social media groups. These questions are mostly close-ended, soliciting either a simple Yes/No answer or a specific solution. The posters often describe specific issues that they are encountering; the replies (comments), on the other hand, may benefit not only the worker who posted the questions but also others who have similar issues or concerns due to the public nature of the conversations.

- Seeking experiences. Workers also elicit opinions from peers who have had similar experiences in an effort to either initiate a discussion about certain topics or, more simply, to find companions. Such posts typically start with language such as "Are there any other people...," or "Did anybody else...". The accumulation of various anecdotes provides workers with a 


\begin{tabular}{|c|c|c|c|}
\hline Code & Definition & Example & Count (\%) \\
\hline $\begin{array}{l}\text { Seeking } \\
\text { solutions }\end{array}$ & $\begin{array}{l}\text { Ask for answers } \\
\text { and solutions to } \\
\text { specific issues directly }\end{array}$ & $\begin{array}{l}\text { Do anyone know if it is possible to drive for uber or } \\
\text { Lyft in the state of New York with seattle Washington } \\
\text { plates just wondering }\end{array}$ & $433(26.1 \%)$ \\
\hline $\begin{array}{l}\text { Seeking } \\
\text { experiences }\end{array}$ & $\begin{array}{l}\text { Ask for similar } \\
\text { experiences from } \\
\text { other members, } \\
\text { often accompanied } \\
\text { with self-disclosure }\end{array}$ & $\begin{array}{l}\text { Mitsubishi Outlander for UberXL? } \\
\text { Anyone drive a Mitsubishi Outlander for UberXL? } \\
\text { I've seen some people talking about how it's the best } \\
\text { since it's cheap and gets good mpg, but then it know } \\
\text { others say they drive an Outlander but don't even } \\
\text { do XL because the third row is too small. Thoughts? }\end{array}$ & $349(21.1 \%)$ \\
\hline $\begin{array}{l}\text { Sharing } \\
\text { experiences }\end{array}$ & $\begin{array}{l}\text { Share personal } \\
\text { experience releated } \\
\text { to gig work }\end{array}$ & $\begin{array}{l}\text { As I was leaving the LAXit with passenger, I saw } \\
3 \text { black and white airport police cars parked in the } \\
\text { LAXit entrance driveway and pulling over random } \\
\text { uber drivers. } \\
\text { They use to harras uber drivers on the waiting lot } \\
\text { for all kind of bullshit things and tickets were } \$ 1000 \\
\text { flat plus } 30 \text {-day impound. Uber covered those tickets } \\
\text { in the beginning, but after some time, they declared, } \\
\text { that tickets and impound fees are on you }\end{array}$ & $346(20.9 \%)$ \\
\hline $\begin{array}{l}\text { Sharing } \\
\text { external } \\
\text { resources }\end{array}$ & $\begin{array}{l}\text { Share pointers to } \\
\text { external sources }\end{array}$ & $\begin{array}{l}\text { "IRS issues warning as Bay Area workers receive } \\
\text { 1099s from Uber, even though they've never driven a } \\
\text { rideshare" } \\
\text { (https://abc7news.com/5964785/) }\end{array}$ & $197(11.9 \%)$ \\
\hline
\end{tabular}

Table 4. Code book for information sharing behavior on social media groups.

good reference by allowing them to compare their own experiences with the experiences of a large number of peer workers.

- Sharing experiences. Members make new posts to share their personal experiences and observations about their gig work, often accompanied by photos or screenshots. The shared information is often time and location sensitive. Frequent topics include personal income, local traffic, business hours, or warnings about bad clients. During the initial outbreak of COVID-19, many workers posted observations about their local gig market.

- Sharing external resources. Besides sharing their subjective experiences and feelings, members of these groups also share external resources. Within this category, the posts primarily contain links to task-relevant information. During COVID-19, crucial information such as changes in government policies or important press releases from gig platforms is often shared in social media groups.

Most interviewees reacted positively to the information they received from various social media groups. Some mentioned that reading about other members' experiences was especially beneficial in preparing themselves for unexpected situations. For example, P12, a part-time Instacart shopper, noted that reading posts about others' shopping experiences were beneficial because she was able to call on common solutions when she encountered a problem.

"One time someone posted about Instacart, ..., sometimes the picture of an item won't match ... the description of the item or how it's named. So that happened today. [According to the post], usually what people do in that instance is they just try to follow what the picture is, and then just double check with a screenshot. I entered the app to 
that customer today, and I was like, 'do you want this fruit bar thing that says or do you want this cereal? That's what the picture is'. They clarified that it was the cereal in the picture. So I was like, 'Okay, great."

In this example, $\mathrm{P} 12$ describes an instance in which gig workers must resolve issues over which they have little control (e.g., technical insufficiency of the platform). At the same time, gig workers still bear the burden of emotional labor, as they learn to communicate these issues with the clients while adapting to the clients' social and emotional needs [26]. Because platforms provide little guidance or training, the workers were forced to turn to the specific, past experiences of their peers for help. Peers had further insight into topics germane to the platform, such as surge algorithm, rating calculation, and deactivation. In general, the language surrounding these topics within the platform-based resources was vague or inscrutable. For example, Uber's official help page cites 'abusing promotions; collusion between riders and drivers; fraudulent or illegitimate disputes over fares; and duplicate accounts' as bases for user account deactivation without disclosing details of what these violations entail. P3, on the other hand, described how reading about another driver being deactivated by Uber because of customer ratings helped him prepare for similar situations in the future.

"I read about, like, how some of these drivers got deactivated and there's no proof, you know, just because some crazy rider said something and... I find that very disturbing how Uber can just deactivate you with absolutely no proof. So, I'd like to be prepared if something like this happens. I put myself in his situation. What would I do in case something like that happens? So, if I got deactivated for nothing I've done wrong, then I would have a problem with that. "

\subsubsection{Affordances of social media groups facilitate the exchange of informational support among gig} workers. We demonstrated that peer workers provide valuable experiences and insight unavailable in informational resources provided by the gig platforms. Coding of the posts in social media groups shows that the majority of posts were for informational purposes; $80 \%$ of the posts in social media groups are either seeking or providing informational support. In this section, we indicate how three major affordances of social media groups - broadcasting, specialization, and retrievability all facilitate the exchange of informational support among gig workers.

The analysis of the social media posts illustrates that by soliciting experiences from other workers, workers were able to gather concrete, experiential knowledge within social media groups. While experiential knowledge can be unique and idiosyncratic, it offers insight into how others experience the same problem, especially when multiple people provide similar evidence. Without broadcasting, or the 'one-to-many' model of social media group communication, the aggregation of such knowledge would not be possible [22]. Because all members can see the questions and responses, social media groups are particularly helpful in sharing support among peers who are ordinarily unable to connect with one another because of the atomization common in physical gig work. The discussion about how to apply for supplemental unemployment insurance (UI), which was first introduced on March 27, 2020, and which allowed qualified applicants to receive an additional $\$ 600$ per week, illustrates this point. A significant number of relevant posts (34 out of 172 total posts that week, 19.8\%) were made between April 20 and May 15 in the Uber NYC group, as the community members collectively made sense of this new policy. In order to develop an understanding of their own situations, members inquired about the UI applications experiences of other workers (e.g., "Guys, anyone got this message after applying for unemployment? I called the number, an automated message says "do not call us, we will call you"), They also sought out solutions by directly asking about specific challenges that they encountered in their application process (e.g., "Question. Does anyone know if you get a call from the labor department to say your 
claim weekly payment is ready now you can claim it by going to labor department website, but when I go to the link ... it doesn't go ahead. Please can anyone tell me how to claim it ?") Although individual workers don't personally know many peer workers, social media groups allow them to obtain useful information, compare their experiences with that of others, and accumulate a large number of data points.

In addition to the affordance of broadcasting, social media groups also offer some degree of specialization that cater to the different needs of the workers. Workers can, therefore, join multiple groups that align with their personal interests. Our study examined groups based on different geographical locations, namely, nation-wide groups vs. location-specific groups. Each group type had different strengths for members who are sharing and seeking experiences. Nation-wide groups such as r/uberdrivers could help workers overcome geographic differences and collect valuable information from across the country. Location-specific groups, on the other hand, allowed workers to collect experiential knowledge that was highly relevant to their local area.

"Reddit people talk about how their areas are doing. Like how the Uber drivers can set their rates in California now. They discuss the PUL, unemployment insurance, how people do in different states, how like the riots affected some areas." (P19, commenting on nation-wide $\mathrm{r}$ /uberdrivers)

"I find that, like, the New York one [group], it's more helpful because someone will say something about like Tops [Friendly Market], or like Dechicos [\& sons] so it's a lot more... Like, I recognize them a lot more. "

(P10, commenting on local Facebook group for New York State)

Finally, text-based social media groups also afford retrievability [57]. In addition to gathering information from a variety of other workers, any member of these groups can retrieve this information using the social media platform's search function. Even though people provide answers to a question initiated by one particular member, the answers can still benefit a wider audience. A number of interviewees described that they used the search function to check if 'someone has a similar situation to me' before asking a question in the group. In this sense, the social media groups serve as knowledge bases where the best answers are collectively sourced and preserved.

4.1.3 Some information carries emotional costs. Some information, particularly personal information shared within the groups makes some members uncomfortable even if they also find it helpful. For example, four interviewees specifically pointed to the so-called "boasting posts," or posts where members share their earnings either by verbal description (e.g., "So Saturday night I did \$XXX in Y hours and Z minutes. How am I doing?") or by attaching a screenshot of their earnings. Interviewees used negative words to describe such posts but still noted the benefits of reading them. P15, for instance, described the trade-offs in reading "gloating posts. "

"I'm not one of the people that ... are posting their earnings like 'look, I got this really big batch with this unicorn that tipped me \$50.' It happened once, but, you know, I'm not gonna gloat about it. Though, it has been useful to get an idea of what it's like in their areas around me. Because when people gloat, they also give a lot of information about particular areas, cause they have no shame about showing pictures with addresses and stuff. So, that gives you an idea of which areas are doing good, which ones are doing bad, which ones have the good tippers, and which ones have bad customers. If it's worth my effort to drive halfway across [location] or not. "

"Ranting" posts intended to share negative experiences were another example of trade-offs, especially ones written in a harsh tone laden with profanity. Interviewees described them as "very 
annoying," especially when they judged the poster to be at fault. P10 recalled her reactions to a post that she did not feel good about:

"When people post about a bad customer experience...I remember one person, they're like, "oh, like, I had to refund all these items, they didn't want any replacements." And it's like, okay, yeah, that's annoying, but at the end of the day, what the customer wants is what the customer wants, so just, like, do it. Many times it just turns out that, like, it's the shopper that was in the wrong."

Ultimately, the two types of trade-offs just described might be the intrinsic costs of experiential knowledge-sharing in peer support groups. While peer workers can provide concrete experiences unavailable from other channels, this information can also be highly subjective and representative of the personal emotional experiences of the posters. Interviewees reported that they seemed to be able to 'extract' the gist of the information, even as they were, inevitably, compelled to carry the emotional labor that accompanied the information.

4.1.4 Fear of competition prevents workers from sharing information in social media groups. Although some interviewees described responding to others' questions and expressed willingness to help out, thirteen out of the twenty interviewees described themselves as "lurkers" in these groups. These users were in the browse-only mode most of the time and would only post if they themselves had a question. While lurkers are widely recognized in all types of online communities [63, 65], four interviewees explicitly identified the fear of competition as the main reason they did not share information, which is less common in other types of online peer support groups. Specifically, they reported not sharing information they believed to be difficult to obtain, such as their "secrets for success." P14 explained why he would not share his strategies for working for Uber in a local Facebook group: "I mean, these are based on my experiences. It took me several months to figure them out. It cannot just be there for free. I paid for it. [The other members] gotta pay for their lessons too."

In particular, experienced members seem to show a sense of indifference towards newer members, despite finding the group useful when they themselves were new. For example, P20 noted how new workers' questions tend to be repetitive:

"Every single day, people were asking the same stuff, like, hey, this is my first time driving. I'm not really sure what to do, any advice? You know, what's, how much money do y'all make? And it's the same stuff every day. It's like, alright, dude, chill, like, please, we get it. It got annoying. It was basically the same stuff every single day, consistently."

Such indifference is not commonly observed in the contexts of social media groups like online health communities. There, many members observe a sense of generalized reciprocity-that is, of paying kindness forward-between members [30]; experienced members, for example, cite 'return the favor' as a primary motivator in providing peer support [96]. In the case of gig workers, one potential explanation is that experienced workers see new workers as someone who would "taking business away" from them, as P16 put:

"Because for me, honestly, every new driver is taking away business from me. You know, every new driver that joins is taking a piece of the pie. And there's only going to be so many customers, and there's basically an unlimited amount of drivers."

P13 added his observation about how the nationwide Reddit and the local Facebook group differ, speculating that the former is more informative because it involves less direct competition.

"Typically, Reddit people, when you ask a question, are more honest and forthcoming because it won't directly affect them. So, if you say, 'what's a good area?' or 'What's the best thing to do for this particular gig?' Or like, for Instacart, 'how to be a good 
shopper?' They're going to honestly tell you the truth. You know, Facebook is basically, especially with the Instacart Facebook groups, they don't want another person to compete with them."

Research in interpersonal information exchanges suggests that individuals weigh the costs with the benefits when deciding whether or not to share information [35, 94]. Even when interviewees provided support to their peers, they were aware of potential competition with peers and were, as a result, reluctant to provide information that might undermine their own interests. One potential explanation of this reluctance, is that the workers' perception of information sharing (i.e., the loss of their competitive edge) outweighs the perceived benefit of group participation. The broadcast nature of social media groups might intensify members' unwillingness to share competitive information because posting the information makes it available to all group members. Providing information about 'sweetspot' (i.e., merchants or communities that usually have lucrative orders) is an example. P19 discussed his rationale when deciding whether or not to share restaurant-related information in the group:

"Like I knew the restaurants and the neighborhood...like there was one particular restaurant that I could pick up, back to back $\$ 30$ orders and only have to drive like five minutes away for each order. [...] Why would I even bother [to post these to the groups]? I mean, whatever job I've ever had, I always take it completely seriously. People need to do their homework. There's always a risk. Say many more people would know about the restaurant and the trick, my chance of getting the order would just be lower. I wouldn't mind, say, letting a friend know if they really asked. But then posting to the group is another thing. "

P19 describes a phenomenon that is not uncommon among physical gig workers - some workers might choose to share competitive information in other channels of, in some cases, smaller size but stronger social bonds, as broadcasting typically shares information among weak social ties instead of strong ones [29]. In fact, none of the interviewees reported making friendships within social media groups (more details in the next sections). Instead, interviewees said that they were more 'active' in an IM group chat comprised of gig workers who were offline acquaintances (P5, P18, both of whom were not part of any online social media groups), as well as an ethnicity-based groups comprised of workers of the same ethnicity (P20) than the social media groups whose size were larger.

\subsection{Emotional support and social ties}

\subsubsection{Emotional support is not as common or well-received as informational support in social media} groups. Emotional support accounts for a much smaller portion of the posts shared in these social media groups than informational support (32.2\% compared with $80 \%$, see Table 5$)$. Two types of emotional support exchange behavior commonly seen in other support groups are the disclosure of negative experiences, thoughts, and feelings, which we label rants in the current paper, and the expression of compassion and concern [28]. As in other types of support groups, the social media groups examined in the current paper provide gig workers with a place to vent and complain about their work-related frustrations $[5,53]$. However, compassion and prayer messages, which are, also, recurring exchanges of emotional support in other types of support groups[87], account for only a minor portion (3.7\%) in the gig worker support groups.

Interviewees' reactions to emotional support in social media groups were mixed. Similar to other social contexts in which participants receive emotional support from peer workers [71], some participants in social media group communication mentioned that the online peer support helped 


\begin{tabular}{|c|c|c|c|}
\hline Code & Definition & Example & Count (\%) \\
\hline Humor & $\begin{array}{l}\text { Post memes, share } \\
\text { humorous images, or } \\
\text { discuss experience } \\
\text { in a joking manner. }\end{array}$ & $\begin{array}{l}\text { If a fart can get through underwear and a pair of jeans, } \\
\text { how can a mask made of cloth save you from covid? } \\
\text { Asking for a friend.. }\end{array}$ & $142(8.6 \%)$ \\
\hline Rant & $\begin{array}{l}\text { Strongly express a } \\
\text { negative emotion } \\
\text { while describing a } \\
\text { personal experience } \\
\text { or making a generic } \\
\text { complaint }\end{array}$ & $\begin{array}{l}\text { Title: Getting Reported By Someone } \\
\text { I really hate how UBER never tells me which customer } \\
\text { had a problem with something I did during a ride. I'm } \\
\text { not asking for names or anything, I get the privacy angle. } \\
\text { But at least give me specifics instead of vague sentences. } \\
\text { Cause when you give me vague statements I won't learn } \\
\text { anything event if I said/did something minor to offend } \\
\text { a customer. } \\
\text { I wanna give the platform the benefit of the doubt. But } \\
\text { all it tells me is that people take advantage to scare the } \\
\text { shit out of their drivers. How do I know this isn't a person } \\
\text { a canceled (like a recent drunk I kicked out) getting } \\
\text { revenge on me? } \\
\text { It's ridiculous. }\end{array}$ & $329(19.9 \%)$ \\
\hline $\begin{array}{l}\text { Compassion } \\
\text { and prayer }\end{array}$ & $\begin{array}{l}\text { Express empathy } \\
\text { compassion, or send } \\
\text { prayers to } \\
\text { other members. }\end{array}$ & $\begin{array}{l}\text { Tomorrow night is amateur night, so I want to encourage } \\
\text { everyone with no drunk-driving experience to stay off the } \\
\text { road. This goes for Uber/Lyft drivers, too, especially in } \\
\text { northern Louisiana. Go out, get drunk, get wasted and } \\
\text { know that someone with years of experience is out } \\
\text { there working, ready to drive you home. You deserve a } \\
\text { night off. (I'll be sober, though...) }\end{array}$ & $61(3.7 \%)$ \\
\hline
\end{tabular}

Table 5. Code book for emotion sharing behavior on social media groups.

them not to feel like outsiders. Learning that they were not alone in dealing with these difficulties gave them a sense of comfort, as well as a sense of community. For example, P17 discussed his experience as he checked the Facebook group when the application crashed.

"Every now and then, the app would crash. And so I pull it up on there [Reddit]. And sure enough, about three or four other people are talking about the same issue. So that was nice. Because it made me feel like I wasn't the only guy- I was having the same problems as everyone else. So it made for a little bit better experience. So, things like that helped out."

The content analysis shows ranting is a common way for gig workers to seek emotional support in the gig-worker social media groups (19.9\%). In health support groups, disclosures of negative experiences (e.g., rants and complaints) are often implicit requests for emotional support and lead others to offer supportive, empathetic responses [95]. However, in the gig-worker groups studied in this paper, even workers seek emotional support via ranting, such ranting is often not well-received. While compassion is provided in some cases, interviewees' reactions to ranting ranged from indifference (e.g., "I ignore them generally. Generally, anybody who's been negative, I just don't bother with them. They're not worth my time.") to strong opposition. One possible reason that interviewees reacted poorly to such posts is that the expression of negative experiences undermines 
the primary informational function of these groups. P5 reflects the trade-off between being able to share emotions and being able to see more information.

"When people post about a bad customer experience. [...] And it's like, okay, so you're just complaining and ranting when all [the] people who need help or have questions about something they're like, 'posts are getting like, buried under that'. So yeah, those are ... not the weird things that people post but just some of the things in life I don't think we need to be sharing that." (edited for clarity)

Another explanation for the lack of emotional support in these online groups is that gig workers get their emotional support from their offline strong ties. When explicitly asked who they talked to or shared feelings with when they felt down during COVID-19, all twenty interviewees mentioned that they relied on strong offline ties such as family and friends to support their emotional needs (e.g., "Yeah, reach out to like family, friends, relatives, relatives, and friends just to talk call but sometimes FaceTime them or I'll call them and stuff I did. That's what I did during the pandemic.") None of the interviewees reported having built new friendships through social media groups. At most, they exchanged contact information, for example, by adding each other as Facebook contacts Two interviewees mentioned instances when the contact in a social media group allowed them to recognize each other offline, for instance, when waiting for a fare at the airport or grabbing food together; however, the pandemic limited these opportunities for offline socializing.

In addition to the core emotional support processes of seeking support through rants and supplying it through expressions of compassion and prayer, members also posted humorous content such as memes or jokes (8.6\%) to uplift the morale of the group or to relieve work-related stress.

4.2.2 Competition, worker heterogeneity, and the structure of social media groups might lead to less emotional support and weaker ties among workers. The content analysis showed that the exchange of emotional support was not as frequent in the gig worker support groups as it is in other types of peer support groups such as online health communities [87]. The formation of strong social ties, which can be both a cause and effect of the exchange of emotional support, is also rarely seen in the social media groups for gig workers [93]. Below, we identified some reasons for the lack of strong ties or deep emotional support in these social media groups.

First, the competitive nature of gig work might prevent peer-to-peer relationship-building as well as displays of empathy, compassion, or genuine concern for one another. Interviewees were clear about their intentions in their peer support group participation; they wanted relevant information, not the exchange of emotional support, as P12 mentioned:

"I'm not the one who talks to other drivers. I joined a group to see if there was any reasonable information. I'm not a fan of being friendly with other drivers. As far as I'm concerned, we're all self-employed. There's nothing we can do to compete, but, you know, we're both sitting on the same corner waiting for an order. You're gonna take things from my own pocket. Why would I be friends with other drivers? I'm not interested in being friendly."

The power asymmetry between gig workers and gig platforms could exacerbate the shared frustration of drivers already in competition with one another. To serve their customers, gig platforms continually hire workers to ensure an adequate labor pool. Many interviewees noted that their local market was 'oversaturated' and that they could no longer earn the same income that they had when they first became gig workers. They were very clear about the ways in which gig platforms undermined them by 'hiring all these people and giving them bonuses to start'. Competition from new workers could contribute to weak ties among peers. For example, P11 was 
an Instacart shopper who described the influx of Instacart shoppers during the COVID-19 pandemic:

"And all of a sudden, everybody started to do Instacart in my area. It was super obvious if you went to the supermarket every day, like you would bump into many other shoppers just in a single trip. They [Instacart] are still hiring like crazy! I mean it is a good way for folks to make some money at this time, but then I had to say that it was much harder to get decent batches than it used to be. "

In addition, gig workers individually vary in their perceptions and uses of the gig platform. Gray and Suri [31], for example, discussed gig workers' heterogeneity of commitment, noting that the gig economy reflected a Pareto distribution. They argued that a small, core group of workers do the bulk of the work, a larger percentage worked regularly as a part-time job, and the vast majority were likely to leave the field after taking only a handful of jobs. The worker's motivation for doing gig work also varies from worker to worker, as some workers view gig work as a leisure activity while others view it as their primary source of income [58]. Such variance might also preclude empathy and understanding between workers with different motivations. P2, an experienced rideshare driver who started in 2016, shared his thoughts about other drivers who started during the pandemic:

"And it's like...you're doing this just for fun. Like, I get it, you're bored, everything's closed, but then you're really screwing some people over. I met a guy at [location omitted] that was a lawyer. And he was just doing this for fun. He's driving around his BMW. I'm just like, I'm not here to judge or anything, but you really need to reevaluate why you're doing this."

The structure of social media groups might also inhibit the exchange of emotional support and building strong personal connections. P8 mentioned the large number of members on social media groups to be an issue. "I'm sure you know, there are hundreds of people on Facebook groups, and you can't, you can't be friends with a hundred people." Indeed, all groups that we examined had over a thousand members. Because members typically interact through asynchronous text-based posts, it may be difficult for them to establish meaningful, personal relationships with one another. Note this is not to say that the formation of strong ties is impossible with such infrastructure since many participants develop strong ties in other support groups; rather, the structure of social media groups might pose additional barriers for gig workers who were less interested in peer friendship. In addition, gig workers might prefer more intimate or more convenient ways of communication such as phone calls or WhatsApp. For example, P5 mentioned that she typically chats with her "Taskrabbit friend" on the phone: "Oh, I talked to him on the phone. Like I called him. Or he called me or, you know, we chat every once in a while."

Language and cultural barriers are other potential factors that prevent workers from exchanging emotional support. Two interviewees explicitly mention that they were immigrants to the country, and both noted that language was a challenge in interacting with peer workers in social media groups. P20 discussed why he would be more talkative in a Brazillian driver WhatsApp group than on Reddit: "For example, I feel much easier to talk with a Brazilian, you know, it's much easier to start a conversation. I speak Portuguese very well. So, you know, it's much better than my English. And sometimes I don't feel confident to speak English with someone, and sometimes I get stuck in some words."

To sum up, while physical gig workers were not motivated to exchange emotional social support and build strong ties in social media groups in the first place, the structure and limitation of social media groups became obstacles, too. 


\subsection{Social media group as a platform for collective action}

4.3.1 Social media groups are not widely used to organize collective action among gig workers. For gig workers who are geographically dispersed, digitally mediated, and thus highly fragmented, social media groups have the potential to help workers organize themselves. Indeed, social media groups have been useful for some contingent workers in the past as they were in the process of organizing labor union activities [84]. However, despite the limited sample size, our study suggests that social media groups are not widely used as a tool to organize collective action among gig workers. To start, none of our interviewees used these groups for labor campaigns or digital activism, and only one of the twenty interviewees had personally participated in a strike.

We then examined two strike incidents initiated by physical gig workers in 2020 - one started by rideshare drivers, and another organized by Instacart shoppers - to analyze the strike-related communication in social media groups. For each strike, we analyzed event-related posts from their corresponding subreddit (i.e., 7 posts from $\mathrm{r} / \mathrm{uberdrivers} \mathrm{and} 10$ posts from $\mathrm{r} /$ InstacartShoppers) and their replies. We found that none of the posts (17 in total) contained member questions or comments regarding the organization of the strike, which were commonly observed in strikes in other contexts [62]. Instead, in these posts, workers expressed their own opinions about strikes, explained their personal reasons and perspectives for choosing whether to strike, and revealed whether they would strike.

On Reddit, gig workers shared mixed, if not more negative opinions, toward the idea of striking. Among the 170 specific comments we analyzed, 16 commenters explicitly stated they were striking or were going to strike, while 41 stated they would not. More people expressed their opinions on the strike without directly stating whether or not they actually planned on participating in the strike. Among these, 30 comments explicitly expressed positive opinions toward the strike by, for instance, highlighting the importance of a strike and persuading or even arguing with opponents On the other hand, 71 comments expressed negative opinions, with many using strong language to argue against it.

Even among those who expressed favorable opinions of the strikes, only one of the 30 commenters claimed that they were the organizers of the strikes or tried to promote the potential benefits of broader unionization, despite this being a theme frequently adopted by labor activists in organizing other strike activities [10]. Rather, supporters attempted to explain their rationale for participating from their perspectives as individuals. For example, they mentioned that they stopped working and went on strike either because there were insufficient earnings from their work or because the work itself could potentially compromise their health. Many supporters believed that the pay from gig platforms was too low, and it was not worthwhile to accept the orders anymore (e.g., "Looking into my ride history, I saw Uber taking an average of 50\% of my riders pay. This is unacceptable. I will not drive again til drivers receive at least $75 \%$ of every ride." ). Others pointed out the financial trade-off between earning money and potentially contracting COVID-19 (e.g., "All of that [income] will be gone, and much more, if you have to go to the hospital for COVID-19. Conditions ARE poor in stores: inventory is uneven, customers are wandering the stores sick and thoughtless of others... it's a mess at times, especially at places like ALDI.").

4.3.2 Reasons for not participating in strikes and collective action. Based on the interviews and analysis of the Reddit posts, collective action and strikes did not receive widespread support from gig workers. Below, we identify several reasons why workers did not participate in the strikes. In summary, while gig workers cite both pragmatic financial reasons and more personal reasons for not taking part in collective action, existing infrastructures such as social media groups do not meet their needs and thus provide workers little support in helping with the strike organization. 
The perceived ineffectiveness of strikes. While some workers did cite personal obstacles to participation (e.g., saying that they "had bills to pay" and hence unable to participate in a strike), the vast majority of commenters opposing the strike questioned its effectiveness and argued that it would not result in the benefits for which the workers were striking in the first place. Their doubts were based on failures of past strikes initiated by gig workers, distrust of the organizers of the strike, as well as the unclear timeline for the strike. Most importantly, workers reported being uncertain about how other workers would react to the strike, raising doubts about whether the strike would reach the necessary threshold number of participants required for any kind of organizational impact. Unlike with traditional strikes, which are typically organized by labor unions and never organized without the approval of the membership, many physical gig workers were unable to determine the percentage of workers who were going to participate in the strike. Workers developed their own ways of estimating how popular the strike was locally. For example, commenters mentioned that they used "how quickly the batches were taken from Instacart App" as an indicator, only to find "I actually was too slow for a $\$ 78$ Bjs batch for 44 items 57 units". Furthermore, in contrast to previous strikes, the Instacart strike in March 2020 introduced novel parameters of a pandemicbased demonstration, for example, concerns about infection and lockdown regulations, which prevented workers from physically gathering, making it even more difficult to gauge popularity and the likely success of their work. Participants in these discussions mentioned their difficulties in monitoring other virtual peers before, eventually, implementing creative methods of observing them.

Another factor that prevented workers from participating in strikes was the fear of being replaced by the platforms. Commenters expressed the view that the strike would be unsuccessful because gig platforms could "get you replaced" by recruiting workers until the market was saturated, and thus "this strike will only hurt you." Workers were aware that the gig platforms could increase their workforce and promote inter-worker competition, but they also felt they could do very little about it. For the Instacart strike, which occurred during the pandemic, commenters mentioned that new workers were rushing in because when the unemployment rate was "estimated to be near $30 \%$," people were "willing" or even "grateful" for the delivery work. While social media groups potentially provided strike supporters an opportunity to use their own behavior as a model for peer workers, only nine out of 100 comments explicitly stated they were going to strike. It seemed that the limited number of individual data points did not convince the majority of the discussion participants to participate.

The interviewees had raised similar concerns about the success of the strike. As $\mathrm{P} 9$, an experienced gig worker who had done both rideshare and delivery, argued: "Unless they can get $90 \%$, or probably $50 \%$ to $60 \%$ or better of the people that actually strike, I don't think it's going to make any kind of difference." The interviewees explained that, because their jobs were highly replaceable, the gig platforms would easily hire new workers if a strike were to happen. As P16, who started food delivery in 2019 after losing his regular job, explained,

"So I think also, these people [advocating for a strike] don't realize how replaceable that we are, you know, it's, there's always going to be the demand for someone to take our position, and there's always going to be someone that's gonna come that can easily do our job. Because it's not that hard. Can you drive a car? Yes or No, boom, you're good. You have every qualification you need."

Again, this is another example in which the power dominance of the gig platforms hurt workers' benefits. Platforms' power to saturate the market not only affected individual workers' income but also harmed their mental well-being as it makes them fear being replaced, and this eventually undermined workers' ability to organize collective action. The interviews also suggested that many 
workers were simply unaware of the strike. Of the twenty interviewees, only five claimed that they knew of a labor campaign related to physical gig work that they could have participated in, and only one actually reported participating. Even though social media groups serve as information hubs for many gig workers, they are still limited in their capacity to effectively publicize their labor action. Moreover, because only a small fraction of gig workers join these social media groups, the majority of gig workers who are not members are even less likely to be aware of these labor campaigns, especially after other channels, like in-person gatherings, became largely unfeasible during the COVID-19 pandemic.

The notion of being an independent contractor. Besides the perceived ineffectiveness of going on strike, many strike opponents on Reddit also emphasized the discrepancy between collective action and their identification as independent contractors. Those who commented on this discrepancy expressed the sense of autonomy that they experienced in decision making, because they had the flexibility to select their own work and hours. Gig workers value this autonomy highly $[46,90]$, and their view of themselves, as independent contractors, ultimately places the onus on them to decide whether to accept or decline an order, as illustrated by the following two Reddit comments:

"Guess the term 'Independent Contractor' is lost on people. If you are an IC to a snow plowing company, do you expect them to keep your trucks running, blades sharpened, provided cold weather attire? An independent contractor is a person or entity contracted to perform work for-or provide services to-another entity as a non-employee." (the Instacart strike)

"Omg thank you. Crossing a picket line?! I didn't see a line outside my house while I logged into Uber and Lyft. There are no scabs because we choose to work. It's our choice. Just as it's your choice to not work. I personally think all the things being demanded is absolutely ridiculous. Literally just need more per mile/min. Keep all the rest of this $s^{* * *}$ out of here. We're independent contractors that can work when we want and don't have to work if we don't want to." (the Uber IPO strike)

The interviewees also stressed that gig work was highly independent work, believing that instead of going on strike, one could individually "choose to do it" or "go and try to find another job" if they were not satisfied with the current conditions for performing their gig jobs. For example, P8, a former Airbnb host who started to do food delivery during the pandemic, shared his thoughts about the strike: "I mean, yes, there are particular safety measures that I would like to have been provided earlier. But it was still my choice to go out and work. It's not like if I didn't go to work, I would get fired."

It is worth noting that the gig platforms have made concentrated efforts to portray their workers as independent contractors. For example, Uber highlighted the slogan "be your own boss" ${ }^{8}$ on their

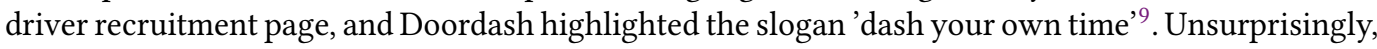
gig platforms emphasize the benefits of being an independent contractor but don't warn workers about the potential income inconsistency of the work. In contrast, false promises are made; for instance, Lyft once claimed that "\$2,300 guaranteed in the first month when you start to drive" and only, in follow up communications, acknowledged that a certain number of rides had to be achieved to obtain the money ${ }^{10}$. While the gig platforms might be intentionally gearing their advertising to

\footnotetext{
${ }^{8}$ https://www.uber.com/us/en/drive/

${ }^{9}$ https://www.doordash.com/dasher/signup/

${ }^{10} \mathrm{https} / /$ www.lyft.com/drive-with-lyft
} 
workers' existing desires, strategies focusing on the benefits of being an independent contractor conflict with the logic of collective action.

Atomization and high variance. Additionally, atomization, or a combination of working isolation over geographically expansive areas and direct competition with one other, makes it more difficult for workers to be empathetic about the problems that other workers experience. For instance, a number of Reddit replies posted information about their earnings to prove that their own rate was satisfactory. They could not relate to people with lower incomes those who were striking. The following comment, for example, draws evidence from the poster and from their in-person social network:

"Sorry but I'm going to keep shopping. I made $\$ 1000$ last week for 37 hours. I had one tip for $\$ 60$ and have gotten multiple cash tips, and handmade thank you cards. It's your choice to do this job. I lost my usual jobs, so I picked this up last week. I got a friend last week, and she made $\$ 1000$ too. Also got my boyfriend's on it, who's in the off-season for football, and he's all about it. I'll take the batches you don't wanna run."

The quote above illustrates how fragmented physical gig workers can be, which makes it difficult for them to identify their shared interests and thus build a cohesive voice.

The high variance among gig workers, or the division between part-time and full-time workers, also hinders the organization of collective activities. A number of interviewees mentioned that they did not intend to do gig work permanently, considering such work to be a leisure activity or a source of supplementary income. These interviewees tended to be less committed and concerned about work conditions than those who relied more heavily on their income from the gig work. For example, P9 explained why he did not pay much attention to the strike: "I'm thankful that I have an education and other skills as backup, so doing Instacart was just not my thing. So maybe that's why I don't care as much." P17 took a similar stance, despite believing that a strike "would certainly have an impact." He stated: "I mean, Doordash is just like a side job for me, a bit like side income from this. I mean, I don't know how serious I'd take the strike. Now, if it was at my current job I might take it seriously." This line of thought is consistent with prior literature [58], which has indicated that the segmentation between full-time and part-time workers could impede the consolidation of shared identities and collective action.

To sum up, while social media groups allow gig workers to share their experiences and opinions regarding collective action freely, the decentralized infrastructure of social media groups is highly aligned with the decentralized nature of the gig economy itself and thus makes it difficult to organize a cohesive voice.

\section{DISCUSSION AND DESIGN IMPLICATIONS}

This paper used a qualitative approach to examine how online social media groups provide informational and emotional support to physical gig workers during the COVID-19 pandemic. We found gig workers were able to gather virtually in these social media groups and thus alleviate the atomization effect. Workers could obtain experiential information, share both positive emotions and frustrations, and discuss labor rights activities with one another in social media groups. However, we also identified a number of factors, such as the fear of competition and the uncertainty about peer workers' activities, that prevented social media groups from being highly effective platforms for informational and emotional support. In the following section, we discuss these factors and propose directions for future research.

First, we recognized the fear of competition as a recurring, central theme that plays a part in the three dimensions - informational support, emotional support, and collective actions - that we studied. Our results show that the fear of competition impedes knowledge sharing, the building of 
emotional rapport, and the willingness to organize collective action in social media groups. While social media groups might not aggravate this fear, their functionality in facilitating communication between workers is certainly undermined. What lies behind the fear of competition is the power imbalance between individual gig workers and the gig work platforms [54]. With relatively low entry barriers to the gig economy, the platforms are almost guaranteed with a continuous influx of new workers and thus have the full power to keep recruiting until they reach market saturation [84]. Our study shows that the power imbalance, which caused the fear of competition among workers, could atomize the workers even further as it weakens the emotional rapport within these groups and undermined workers' ability to unionize, thus possibly perpetuating a negative feedback loop that enlarges the power gap between workers and platforms. As HCI researchers, we need to recognize these fundamental problems faced by gig workers and take them into account in our design solutions.

Second, our results demonstrate that the vast majority of the information shared in social media groups is experiential knowledge contributed by individual gig workers. While the concrete experiential knowledge affords several unique strengths, it is worth noting that such information tends to offer specific snippets about one's task-relevant experiences. Prior work on social media groups organized by Airbnb hosts [34], entrepreneurs [38], and digital nomads [79] all noted that their groups provide information on long-term professional development. However, neither the interviewees' recounts nor the content analysis in our study shows that. As gig work is infamous for its lack of career development, future researchers might consider leveraging social media groups to provide more long-term informational support in addition to the experiential knowledge currently shared in the groups.

Finally, our work examines gig workers' current practices in adopting pre-existing groupware infrastructures (i.e., social media groups like Facebook and Reddit). We found that, while features like broadcasting and group specialization facilitated the exchange of information support, others, such as the decentralized structure, did not help workers build emotional bonds. Meanwhile, HCI researchers have designed groupware systems that cater to gig workers' characteristics and needs. For example, prior work on mTurk workers designed the online community 'Dynamo', which supported the mTurk community in forming collective efforts and was deemed as a huge success [74]. Similarly, we encourage future research to leverage the findings presented in this work to design groupware systems that better fit gig workers' needs. For example, we found that workers lack confidence in the effectiveness of labor rights activities because they feel uncertain about how many other workers would participate. System design for physical gig workers could thus increase the visibility of individual workers' actions and provide workers with a more comprehensive view of the labor activity.

\section{LIMITATION}

This work has several limitations. Our recruitment methods might be biased. We required the interviews to be done in English, which might make our study inaccessible to many gig workers who do not have a confident grasp of English. Our content analysis is also based on social media groups where English is the primary language, which again might not represent immigrants who are now an essential part of the workforce in the gig industry. Future work should explore how marginalized populations, such as immigrant gig workers, obtain and provide support via social media groups. Our interviewees are also disproportionately biased towards a more tech-savvy sample, despite our best efforts in dealing with limited in-person recruitment during COVID-19. Social media groups would naturally attract workers who are younger and more familiar with information communication technologies, and thus it is unclear, based on our research, how social media groups could help with the challenges faced by workers in general. Our results are obtained 
from a small sample of data, with 20 interviews and content analysis on 1,321 social media group posts. The results presented in this paper will be greatly strengthened by future work that employs a different research method.

Because we specifically analyze data from strikes that are already underway and, generally, widely reported by traditional media, our analysis on how social media groups facilitate the organization of collective actions among gig workers is also limited. In future research, we could examine how social media groups help spread information about strikes during their earliest stages of organization and initiation.

\section{CONCLUSION}

In this paper, we examined how online social media groups provide informational and emotional support to physical gig workers during the COVID-19 pandemic using a combination of semistructured interviews and content analysis of social media groups. We found that workers were able to use these groups to obtain experiential knowledge from their peers, build connections, and organize collective action. However, we identified a reluctance among workers to share strategic information where there was a perceived risk of being competitively disadvantaged. In addition, due to the diversity among gig workers, workers have limited empathy with each other, which further undermined the provision of emotional support. While social media groups could potentially become places where workers organize collective efforts, several factors, including the uncertainty of other workers' activities and their understanding of the independent contractor status, deterred the development of a collective voice.

\section{ACKNOWLEDGMENTS}

We would like to thank Yuhan Liu for her support in qualitative coding. We would also like to thank all our interviewees for their insights. This work was supported by the National Science Foundation (NSF) under Award 1952085.

\section{REFERENCES}

[1] [n.d.]. Uber and Lyft Drivers in California Will Remain Contractors.

[2] 2021. US unions not fazed by Amazon setback and vow to keep up the organizing fight. https://www.theguardian. com/us-news/2021/apr/13/us-unions-amazing-organizing-effort-drive

[3] Syed Ishtiaque Ahmed, Nicola J Bidwell, Himanshu Zade, Srihari H Muralidhar, Anupama Dhareshwar, Baneen Karachiwala, Cedrick N Tandong, and Jacki O’Neill. 2016. Peer-to-peer in the Workplace: A View from the Road. In Proceedings of the 2016 CHI Conference on Human Factors in Computing Systems. 5063-5075.

[4] Andrea Alarcon and Mary L Gray. [n.d.]. Future of Work Global Labor. Literature Review. Learning, Evaluation and Research Activity II (LER II).

[5] Mashael Yousef Almoqbel and Donghee Yvette Wohn. 2019. Individual and Collaborative Behaviors of Rideshare Drivers in Protecting their Safety. Proceedings of the ACM on Human-Computer Interaction 3, CSCW (2019), 1-21.

[6] Uttam Bajwa, Denise Gastaldo, Erica Di Ruggiero, and Lilian Knorr. 2018. The health of workers in the global gig economy. Globalization and health 14, 1 (2018), 1-4.

[7] Chris Benner, Erin Johansson, Kung Feng, and Hays Witt. 2020. On-Demand and on-the-edge: Ride-hailing and Delivery Workers in San Francisco. https://transform.ucsc.edu/on-demand-and-on-the-edge/

[8] Thor Berger, Carl Benedikt Frey, Guy Levin, and Santosh Rao Danda. 2019. Uber happy? Work and well-being in the 'gig economy'. Economic Policy 34, 99 (2019), 429-477.

[9] danah boyd. 2010. Social network sites as networked publics: Affordances, dynamics, and implications. Networked self: Identity, community, and culture on social network sites 39 (2010), 58.

[10] Alex Bryson, Rafael Gomez, and Paul Willman. 2010. Online social networking and trade union membership: What the Facebook phenomenon truly means for labor organizers. Labor History 51, 1 (2010), 41-53.

[11] Eliane Bucher, Christian Fieseler, Christoph Lutz, and Gemma Newlands. 2020. Shaping emotional labor practices in the sharing economy. In Theorizing the Sharing Economy: Variety and Trajectories of New Forms of Organizing. Emerald Publishing Limited. 
[12] Ben Chapman and Valerie Bauerlein. 2020. U.S. Coronavirus Cases Rose to Monthly Record in July. https://www.wsj. com/articles/coronavirus-latest-news-080220-11596361041

[13] Kathy Charmaz and Linda Liska Belgrave. 2007. Grounded theory. The Blackwell encyclopedia of sociology (2007).

[14] Ruth Berins Collier, VB Dubal, and Christopher Carter. 2017. Labor platforms and gig work: the failure to regulate. (2017).

[15] Kate Conger, Adam Satariano, and Mike Isaac. 2020. Pandemic Erodes Gig Economy Work. https://www.nytimes. com/2020/03/18/technology/gig-economy-pandemic.html

[16] Munmun De Choudhury and Sushovan De. 2014. Mental health discourse on reddit: Self-disclosure, social support, and anonymity. In Eighth international AAAI conference on weblogs and social media.

[17] Willem De Groen, Ilaria Maselli, and Brian Fabo. 2016. The Digital Market for Local Services: A one-night stand for workers? An example from the on-demand economy. An Example from the On-Demand Economy (April 4, 2016). CEPS Special Report 133 (2016).

[18] Megan Rose Dickey. 2020. Gig workers say they are struggling to get personal protective equipment from companies. https://techcrunch.com/2020/04/16/gig-workers-personal-protective-equipment/

[19] Sarah A Donovan, David H Bradley, and Jon O Shimabukuru. 2016. What does the gig economy mean for workers? Congressional Research Service (2016). https://ecommons.cornell.edu/xmlui/bitstream/handle/1813/79155/CRS_What_ does_the_gig_economy_mean.pdf

[20] Veena B Dubal. 2017. The Drive to Precarity: A Political History of Work, Regulation, \& Labor Advocacy in San Francisco's Taxi \& Uber Economics. Berkeley f. Emp. \& Lab. L. 38 (2017), 73.

[21] Benjamin G Edelman and Michael Luca. 2014. Digital discrimination: The case of Airbnb. com. Harvard Business School NOM Unit Working Paper 14-054 (2014).

[22] Nicole B Ellison and Jessica Vitak. 2015. Social network site affordances and their relationship to social capital processes. The handbook of the psychology of communication technology 32 (2015), 205-228.

[23] Sarah Feldman. 2019. Infographic: What Is the Top Paying Gig Job? https://www.statista.com/chart/19411/gig-workpay/

[24] Bronwyn Frey. 2020. Platform Labor and In/Formality: Organization among Motorcycle Taxi Drivers in Bandung, Indonesia. Anthropology of Work Review 41, 1 (2020), 36-49.

[25] Eric Gilbert and Karrie Karahalios. 2009. Predicting tie strength with social media. In Proceedings of the SIGCHI conference on human factors in computing systems. 211-220.

[26] Mareike Glöss, Moira McGregor, and Barry Brown. 2016. Designing for labour: uber and the on-demand mobile workforce. In Proceedings of the 2016 CHI conference on human factors in computing systems. 1632-1643.

[27] John Godard. 1992. Strikes as collective voice: A behavioral analysis of strike activity. ILR Review 46, 1 (1992), $161-175$.

[28] Rebecca J Gooden and Helen R Winefield. 2007. Breast and prostate cancer online discussion boards: a thematic analysis of gender differences and similarities. Journal of Health Psychology 12, 1 (2007), 103-114.

[29] Mark S Granovetter. 1973. The strength of weak ties. American journal of sociology 78, 6 (1973), 1360-1380.

[30] Kurt Gray, Adrian F Ward, and Michael I Norton. 2014. Paying it forward: Generalized reciprocity and the limits of generosity. Journal of experimental psychology: General 143, 1 (2014), 247.

[31] Mary L Gray and Siddharth Suri. 2019. Ghost work: How to stop Silicon Valley from building a new global underclass. Eamon Dolan Books.

[32] Anikó Hannák, Claudia Wagner, David Garcia, Alan Mislove, Markus Strohmaier, and Christo Wilson. 2017. Bias in online freelance marketplaces: Evidence from taskrabbit and fiverr. In Proceedings of the 2017 ACM conference on computer supported cooperative work and social computing. 1914-1933.

[33] Arlie Russell Hochschild. 2012. The managed heart: Commercialization of human feeling. Univ of California Press.

[34] Maya Holikatti, Shagun Jhaver, and Neha Kumar. 2019. Learning to Airbnb by engaging in online communities of practice. Proceedings of the ACM on Human-Computer Interaction 3, CSCW (2019), 1-19.

[35] Gary Hsieh, Robert Kraut, Scott E Hudson, and Roberto Weber. 2008. Can markets help? Applying market mechanisms to improve synchronous communication. In Proceedings of the 2008 ACM conference on Computer supported cooperative work. 535-544.

[36] Julietta Hua and Kasturi Ray. 2018. Beyond the precariat: race, gender, and labor in the taxi and Uber economy. Social Identities 24, 2 (2018), 271-289.

[37] Lei Vincent Huang and Piper Liping Liu. 2017. Ties that work: Investigating the relationships among coworker connections, work-related Facebook utility, online social capital, and employee outcomes. Computers in Human Behavior 72 (2017), 512-524.

[38] Julie Hui, Nefer Ra Barber, Wendy Casey, Suzanne Cleage, Danny C Dolley, Frances Worthy, Kentaro Toyama, and Tawanna R Dillahunt. 2020. Community Collectives: Low-tech Social Support for Digitally-Engaged Entrepreneurship. In Proceedings of the 2020 CHI Conference on Human Factors in Computing Systems. 1-15. 
[39] Abigail Hunt, Emma Samman, Sherry Tapfuma, Grace Mwaura, Rhoda Omenya, Kay Kim, Sara Stevano, and Aida Roumer. 2019. Women in the gig economy: paid work, care and flexibility in Kenya and South Africa. (2019).

[40] Lyft Inc. [n.d.]. Helping Lyft's driver community - COVID-19. https://www.lyft.com/safety/coronavirus/driver

[41] Uber Inc. [n.d.]. Why is My Local GLH Closed? https://help.uber.com/driving-and-delivering/article/why-is-mylocal-glh-closed?nodeId=e882c6fc-465c-498b-ad48-b9216020fa9c

[42] Uber Technologies Inc. 2020. An update on COVID-19 financial assistance. https://www.nytimes.com/2020/03/30/ business/economy/coronavirus-instacart-amazon.html

[43] Instacart. [n.d.]. https://covidresponse.instacart.com/shopper-resources/

[44] Nura Jabagi, Anne-Marie Croteau, Luc K Audebrand, and Josianne Marsan. 2019. Gig-workers' motivation: thinking beyond carrots and sticks. Journal of Managerial Psychology (2019).

[45] Mohammad Hossein Jarrahi and Will Sutherland. 2019. Algorithmic Management and Algorithmic Competencies: Understanding and Appropriating Algorithms in Gig work. In International Conference on Information. Springer, 578-589.

[46] Mohammad Hossein Jarrahi, Will Sutherland, Sarah Beth Nelson, and Steve Sawyer. 2020. Platformic Management, Boundary Resources for Gig Work, and Worker Autonomy. Computer Supported Cooperative Work (CSCW) 29, 1 (2020), 153-189.

[47] Zhou Jiang and Xiaowen Hu. 2016. Knowledge sharing and life satisfaction: The roles of colleague relationships and gender. Social Indicators Research 126, 1 (2016), 379-394.

[48] Arne L Kalleberg and Michael Dunn. 2016. Good jobs, bad jobs in the gig economy. LERA for Libraries 20, 1-2 (2016).

[49] Vaishnav Kameswaran, Lindsey Cameron, and Tawanna R Dillahunt. 2018. Support for social and cultural capital development in real-time ridesharing services. In Proceedings of the 2018 CHI Conference on Human Factors in Computing Systems. 1-12.

[50] Melissa G Keith, Peter D Harms, and Alexander C Long. 2020. Worker Health and Well-Being in the Gig Economy: A Proposed Framework and Research Agenda. In Entrepreneurial and Small Business Stressors, Experienced Stress, and Well-Being. Emerald Publishing Limited.

[51] Vera Khovanskaya, Phoebe Sengers, and Lynn Dombrowski. 2020. Bottom-Up Organizing with Tools from On High: Understanding the Data Practices of Labor Organizers. In Proceedings of the $2020 \mathrm{CHI}$ Conference on Human Factors in Computing Systems. 1-13.

[52] Eliscia Kinder, Mohammad Hossein Jarrahi, and Will Sutherland. 2019. Gig Platforms, Tensions, Alliances and Ecosystems: An Actor-Network Perspective. Proceedings of the ACM on Human-Computer Interaction 3, CSCW (2019), 1-26.

[53] Neha Kumar, Nassim Jafarinaimi, and Mehrab Bin Morshed. 2018. Uber in Bangladesh: The Tangled Web of mobility and justice. Proceedings of the ACM on Human-Computer Interaction 2, CSCW (2018), 1-21.

[54] Airi Lampinen, Christoph Lutz, Gemma Newlands, Ann Light, and Nicole Immorlica. 2018. Power struggles in the digital economy: platforms, workers, and markets. In Companion of the 2018 ACM Conference on Computer Supported Cooperative Work and Social Computing. 417-423.

[55] Min Kyung Lee, Daniel Kusbit, Evan Metsky, and Laura Dabbish. 2015. Working with machines: The impact of algorithmic and data-driven management on human workers. In Proceedings of the 33rd annual ACM conference on human factors in computing systems. 1603-1612.

[56] Vili Lehdonvirta. 2016. Algorithms that divide and unite: Delocalisation, identity and collective action in 'microwork'. In Space, place and global digital work. Springer, 53-80.

[57] Jun Liu. 2018. Who speaks for the past? Social media, social memory, and the production of historical knowledge in contemporary China. International fournal of Communication 12 (2018), 21.

[58] Ning F Ma and Benjamin V Hanrahan. 2019. Part-Time Ride-Sharing: Recognizing the Context in which Drivers Ride-Share and its Impact on Platform Use. Proceedings of the ACM on Human-Computer Interaction 3, GROUP (2019), $1-17$.

[59] Ning F Ma, Chien Wen Yuan, Moojan Ghafurian, and Benjamin V Hanrahan. 2018. Using Stakeholder Theory to Examine Drivers' Stake in Uber. In Proceedings of the 2018 CHI Conference on Human Factors in Computing Systems. 1-12.

[60] Brenton J Malin and Curry Chandler. 2017. Free to work anxiously: Splintering precarity among drivers for Uber and Lyft. Communication, Culture \& Critique 10, 2 (2017), 382-400.

[61] Elizabeth B Marquis, Sangmi Kim, Rasha Alahmad, Casey S Pierce, and Lionel P Robert Jr. 2018. Impacts of perceived behavior control and emotional labor on gig workers. In Companion of the 2018 ACM conference on computer supported cooperative work and social computing. 241-244.

[62] Dan Mercea. 2013. Probing the implications of Facebook use for the organizational form of social movement organizations. Information, Communication \& Society 16, 8 (2013), 1306-1327. 
[63] Michael Muller, N Sadat Shami, David R Millen, and Jonathan Feinberg. 2010. We are all lurkers: consuming behaviors among authors and readers in an enterprise file-sharing service. In Proceedings of the 16th ACM international conference on Supporting group work. 201-210.

[64] Gemma Newlands, Christoph Lutz, and Christian Fieseler. 2018. Collective action and provider classification in the sharing economy. New Technology, Work and Employment 33, 3 (2018), 250-267.

[65] Blair Nonnecke and Jenny Preece. 2000. Lurker demographics: Counting the silent. In Proceedings of the SIGCHI conference on Human Factors in Computing Systems. 73-80.

[66] Peter Norlander, Nenad Jukic, Arup Varma, and Svetlozar Nestorov. 2020. The effects of technological supervision on gig workers: organizational control and motivation of Uber, taxi, and limousine drivers. The International fournal of Human Resource Management (2020), 1-25.

[67] Sara Ashley O’Brien. [n.d.]. Uber has more work to do winning over drivers. https://money.cnn.com/2017/12/18/ technology/uber-drivers-180-days-of-change/index.html

[68] Sara Ashley O’Brien. 2019. Why Uber and Lyft drivers are striking. https://www.cnn.com/2019/05/07/tech/uberdriver-strike-ipo/index.html

[69] Sara Ashley O’Brien. 2020. Prop 22 passes in California, exempting Uber and Lyft from classifying drivers as employees. https://www.cnn.com/2020/11/04/tech/california-proposition-22/index.html

[70] Kirsty Grant Pandey and Manish. 2021. Uber pay changes: Gig economy workers on what it could mean for them. https://www.bbc.com/news/newsbeat-56433922

[71] Stephen A Rains. 2018. Coping with illness digitally. MIT Press.

[72] Noopur Raval and Paul Dourish. 2016. Standing out from the crowd: Emotional labor, body labor, and temporal labor in ridesharing. In Proceedings of the 19th ACM Conference on Computer-Supported Cooperative Work \& Social Computing. 97-107.

[73] Alex Rosenblat and Luke Stark. 2016. Algorithmic labor and information asymmetries: A case study of Uber's drivers. International fournal of Communication 10 (2016), 27.

[74] Niloufar Salehi, Lilly C Irani, Michael S Bernstein, Ali Alkhatib, Eva Ogbe, and Kristy Milland. 2015. We are dynamo: Overcoming stalling and friction in collective action for crowd workers. In Proceedings of the 33rd annual ACM conference on human factors in computing systems. 1621-1630.

[75] Noam Scheiber and Kate Conger. 2020. Strikes at Instacart and Amazon Over Coronavirus Health Concerns. https: //www.nytimes.com/2020/03/30/business/economy/coronavirus-instacart-amazon.html

[76] Joseph Seering, Felicia Ng, Zheng Yao, and Geoff Kaufman. 2018. Applications of Social Identity Theory to Research and Design in Computer-Supported Cooperative Work. Proceedings of the ACM on Human-Computer Interaction 2 , CSCW (2018), 1-34.

[77] Cathy Donald Sherbourne and Anita L Stewart. 1991. The MOS social support survey. Social science \& medicine 32,6 (1991), 705-714.

[78] Daniel Spurk and Caroline Straub. 2020. Flexible employment relationships and careers in times of the COVID-19 pandemic.

[79] Will Sutherland and Mohammad Hossein Jarrahi. 2017. The gig economy and information infrastructure: The case of the digital nomad community. Proceedings of the ACM on Human-Computer Interaction 1, CSCW (2017), 1-24.

[80] Will Sutherland, Mohammad Hossein Jarrahi, Michael Dunn, and Sarah Beth Nelson. 2020. Work precarity and gig literacies in online freelancing. Work, Employment and Society 34, 3 (2020), 457-475.

[81] Arianna Tassinari and Vincenzo Maccarrone. 2020. Riders on the storm: Workplace solidarity among gig economy couriers in Italy and the UK. Work, Employment and Society 34, 1 (2020), 35-54.

[82] Rannie Teodoro, Pinar Ozturk, Mor Naaman, Winter Mason, and Janne Lindqvist. 2014. The motivations and experiences of the on-demand mobile workforce. In Proceedings of the 17th ACM conference on Computer supported cooperative work \& social computing. 236-247.

[83] Steven Vallas and Juliet B Schor. 2020. What Do Platforms Do? Understanding the Gig Economy. Annual Review of Sociology 46 (2020).

[84] Kurt Vandaele. 2020. Collective Resistance and Organizational Creativity Amongst Europe's Platform Workers: A New Power in the Labour Movement? Work and Labour Relations in Global Platform Capitalism, Forthcoming (2020).

[85] Jessica Vitak and Nicole B Ellison. 2013. 'There'sa network out there you might as well tap': Exploring the benefits of and barriers to exchanging informational and support-based resources on Facebook. New media \& society 15, 2 (2013), 243-259.

[86] Leah F Vosko. 2006. Precarious employment: Understanding labour market insecurity in Canada. McGill-Queen's Press-MQUP.

[87] Yi-Chia Wang, Robert E. Kraut, and John. M. Levine. 2015. Eliciting and Receiving Online Support: Using ComputerAided Content Analysis to Examine the Dynamics of Online Social Support. Fournal of Medical Internet Research 17, 4 (2015), e99. 
[88] Juliet Webster. 2016. Microworkers of the gig economy: separate and precarious. In New Labor Forum, Vol. 25. SAGE Publications Sage CA: Los Angeles, CA, 56-64.

[89] Alex Wood and Vili Lehdonvirta. 2019. Platform labour and structured antagonism: Understanding the origins of protest in the gig economy. Available at SSRN 3357804 (2019).

[90] Alex J Wood, Mark Graham, Vili Lehdonvirta, and Isis Hjorth. 2019. Good gig, bad gig: autonomy and algorithmic control in the global gig economy. Work, Employment and Society 33, 1 (2019), 56-75.

[91] Alex J Wood, Vili Lehdonvirta, and Mark Graham. 2018. Workers of the Internet unite? Online freelancer organisation among remote gig economy workers in six Asian and African countries. New Technology, Work and Employment 33, 2 (2018), 95-112.

[92] Jamie Woodcock and Mark Graham. 2019. The gig economy: a critical introduction. Polity.

[93] Kevin Wright. 2012. Similarity, network convergence, and availability of emotional support as predictors of strongtie/weak-tie support network preference on Facebook. Southern Communication fournal 77, 5 (2012), 389-402.

[94] Zhijun Yan, Tianmei Wang, Yi Chen, and Han Zhang. 2016. Knowledge sharing in online health communities: A social exchange theory perspective. Information \& Management 53, 5 (2016), 643-653.

[95] Diyi Yang, Zheng Yao, Joseph Seering, and Robert Kraut. 2019. The channel matters: Self-disclosure, reciprocity and social support in online cancer support groups. In Proceedings of the 2019 CHI Conference on Human Factors in Computing Systems. 1-15.

[96] Zheng Yao, Diyi Yang, John M Levine, Carissa A Low, Tenbroeck Smith, Haiyi Zhu, and Robert E Kraut. 2021. Join, Stay or Go? A Closer Look at Members' Life Cycles in Online Health Communities. Proceedings of the ACM on Human-Computer Interaction 5, CSCW (2021), 1-22.

Received October 2020 ; revised April 2021 ; accepted July 2021 